\title{
The age and the psychological conditions of the manipulative behavior of preschool children
}

\begin{abstract}
Preschool age is described as a sensitive period for the development of children's manipulations. Examples of children's tricks and gimmicks are correlated with the age characteristics of the child of 3-7 years.
\end{abstract}

Keywords: psychological manipulation, preschool age, children's manipulation, age prerequisites manipulative behavior
Volume 9 Issue 4 - 2018

\author{
Olga $\vee$ Kozachek \\ Department of Pedagogy, Early Childhood Education, Volgograd \\ State Pedagogical University, Russia
}

Correspondence: Olga $\vee$ Kozachek, Associate Professor
of Pedagogy, Early Childhood Education,Volgograd State
Pedagogical University, Russia, Email kozachek@yandex.ru

Received: June 26, 2018 | Published: July 19, 2018

\section{Opinion}

The psychological impact on the person covertly and cunningly used to achieve a unilateral advantage, which bears the character of the subject-object, called psychological manipulation. A single application of psychological manipulation in interpersonal communication as effective, but not a "head-on" exposure is justified. However, the total manipulation destroys a person, causes serious psychosomatic changes, moral distortions, problems with regard to the subject itself, the destruction of relationships with other people. Distribution of psychological manipulation in the various spheres of social life make the theme of "reification" of human topical subject of study. The projection of adult relationships observed in the interaction of preschool children. Analysis of the development and installation of manipulative manipulative behavior of children is important in building the prospects of the current pre-school education. The purpose of this material is to consider the age and psychological potential manipulative manifestations in children 3-7 years.

During the 2009-2018 GG to discuss the current state of the problem of children's manipulations we invited professionals directly related to the education of preschool children. In our study involved 188 teachers, music teachers, instructors in physical education preschool Volgograd and the Volgograd region (Russia). Their reflections and examples from the experience we have summarized and published earlier. ${ }^{1}$ All teachers have listed more than 160 children's tricks, some of them are shown here for illustration and are indicated in italics. Most of the experts met in their practice with children's manipulations. Among the most popular methods of manipulative released "disease", lies, hysteria. preschoolers are traded often they use other people's weaknesses, flatter, give insincere promises refer to their own weakness, manipulated "love." Common is the use of his or someone else's authority, setting up people against each other, the formation of a sense of guilt. Less common, but no less effective controls are stubborn, gifts "supposedly the other, but in reality itself", complaints, denunciations, threats, blackmail, bribery adult or peer, the desire "to bring down the interlocutor confused" and so forth.

Such a variety of children's manipulation is not accidental. Preschool period is favorable for the testing of tricks, tricks, intrigues. In this age of changing social situation of development, transformed the leading type of activity, there are serious changes in the personality and cognitive sphere of children. Speaking about the reasons for "reification" of another person, the scientists called manipulation of the social-caused phenomenon. Modern society, the culture, the people around them translate the growing person to a favorable attitude to the cunning, subterfuge, intrigue, skill in their implementation. ${ }^{2}$ Preschool age is a period in which the child is guided in the basic sense of human activity, mastering tasks, motives, norms of human relations. ${ }^{3}$ This places high demands on the content of education for children 3-7 years. But, rem utilitarian approach to the person, is totally unacceptable in a culture of human dignity, according to VI Slobodchikova, ${ }^{4}$ still has a place in the education of preschool children. Fictional characters, historical, political figures, advertising and cartoons, as well as relatives and teachers are the social adult manipulation.

As a leading activity preschooler stands role-playing game. Of great importance for mental development also acquire communication, productive activities, the perception of literary works, educational activity. New activities entail the formation of new motives, and new requirements define new means of achieving this goal. Interest in the adult world, the desire to act as an adult to enter the adult world can be implemented in an effort to manipulate others as an adult: In response to the mother's threat: "If you do not clean up their toys, I ..." the child may endanger himself, "Mom I will not eat if you are ... ". During the pre-school age increases the differentiation process in the children's collective: some children are becoming popular, others reject. In relation to peers motives develop pride, competition, self-assertion. ${ }^{5}$ Manipulation may be a means of implementing emerging motives: "The child, which is popular among children, clearly decides with whom to be friends with and who not, and deftly puts the conditions for those who want to communicate with him." The desire to raise the status, authority and subjugate others, express their superiority becomes the driving force behind such manipulations. On the child's position in the peer group is influenced by many factors, most of which, according to Smirnova $\mathrm{EO}^{6}$ is empathy and assist peers. Manipulative techniques, on the other hand, break down interpersonal relationships, while helping to achieve situational purposes: "One child said to his companion on the game, he had a bad toy, and it is in such toys do not play, because it is big. Comrade toy throws, and her arm a couple of minutes it takes. "

Preschool age - period of the emotional sphere, the assimilation of norms of behavior and moral sentiments, ethical formation of primary instances. A special place is occupied by moral motives related to the 
attitude towards other people, understanding their actions and actions of others. Older preschoolers can already see signs of genuine care for the loved ones or successful examples of the object, the user relationship to peers: "Vova wanted to take the car, but it was ahead of Peter. Then Vova, going to Pete, said that the boys play ball. Peter ran to the boys, and Vova took the car "and adults" Stepan (4 years 5 months) are often, if it wants to get the toy from his mother, she begins to whine, beg, sobbing. And he realizes that adults strongly irritating. Therefore achieves the desired fast. " According to L. Kohlberg [op. 4] the majority of children of preschool age, because of the nature of his thinking, are on domoralnom level of moral reasoning actions. morality for the child - something outside, it complies with the rules established by adults, for purely selfish reasons. a child often resorts to lies to get a promotion or to avoid punishment, "On the table lay a sweet, next was only Lera and candy was not after a while. I ask: "Where did? Lera looks at me with honest eyes: "I do not know. It's not me!". Children lie, as the VS Muhina ${ }^{5}$ can also occur as a consequence of the recognition of unrealized claims. Manipulation in the form of lies in this case arise out of a sense of frustration, the desire to be "no worse": "The child liked the toy, he took her by telling other kids: It's my toy! I bought her mom. "It is important to differentiate between a lie and a children's fantasy in such situations. Manipulative lie always selfish unlike manifestation of the development of the imagination.

The trick, tricks, blackmail, threats, tantrums and used by children as a result of jealousy: "When you start to feel sorry for the younger, the older purposely falls and starts to moan loudly, and came to regret it too." Revnost multifaceted, it may be manifested in psychosomatic diseases, behavioral disorders, etc. autoaggression. These means can be used to conscious or unconscious control object jealous. Children's jealousy - is another example of unrealized claims for recognition and the reason manipulative displays of preschool children: "Secretly hide the game cube, do not allow to play, when the game goes to the advantage of the partner." Even as a child the child learns to feel shame for their tendency to lie and envy. The reaction of adults to negative behavioral manifestations of the data depends on whether they will lock.

By the end of the age appears arbitrary behavior of the child is formed subordination motives, deliberate and arbitrary are the motives, including manipulative. DB El'konin, ${ }^{3}$ characterizing the personality development of the preschool child, describes cases of child stubbornness at the senior preschool age, which is well recognized by the child as an unfair and improper desire in whatever was to have his own. Children tend to take into account the consequences of their obstinacy and show it more often in relation to the adult, from which it goes unpunished, and effective for children. Some older preschoolers is a pleasure to see the impotence of adults, especially if the surrounding peers react to it with laughter. The mechanism of emotional anticipation of the effects of the activities described in detail A. Zaporozhets [op. 4], it is the basis of emotional regulation actions of the preschool child. Even before the child starts to act, he has an emotional image, reflecting and future results, and his praise from adults. Emotionally anticipating the consequences of their behavior, the child already knows in advance, good or bad, he is going to do. In cases where it feels relatively safe, the child can manipulate consciously.

The effectiveness of children's manipulation is largely due to developing the child's ability to control the symptoms of their own and others' experiences. In contrast to the three years of a child 5-6 years of preschool can restrain the stormy, dramatic expression of feelings. Also, the child learns the forms of expression of delicate shades of experiences made public through attitudes, facial expressions, gestures, postures, movements and tone of voice. ${ }^{7}$ This helps not only effectively read the experiences of other people, but also to clearly express their emotional state, true, or desired to control other "false hugs and kisses," "Not real tears," "The child wants to go home to my mother, knowing that the right to call mom It fails, so it mimics the symptoms of the disease, tearfulness, knowing that out of concern for the health educator may cause mother or someone from the family. " The assimilation of the child rules and regulations, which are regulators of its behavior through the study of regulatory complaints of children described VA Gorbachev [op. 10]. Psychological nature of children's complaints analyzed LN Abramova \& AT Ruzskaya. ${ }^{8}$ Psychological manipulation of children's complaint becomes if the child consciously or unconsciously wants to use an adult for achieving the desired target him, "The child, whose accidentally grazed, suddenly falls like jerks and starts to weep loudly, demanding punishment for the alleged perpetrator" "Wanting to have a toy that is in the hands of another child, he would complain to him that the child was punished, and the toy would got to it." The above examples manipulative can be correlated with different types of complaints.

Of course, not every case of the manifestation of obstinacy, whims, children's complaints, lying, stealing, aggression, jealousy is a psychological manipulation. On belonging to the category of reception described us the phenomenon under study indicates:

\section{The presence of psychological influence.}

2. Manipulator related to another as a means of achieving its goal.

3. The desire to receive the unilateral gain.

4. The hidden nature of the impact.

5. Use of psychological strength play on the weaknesses (use of psychological vulnerability).

6. Causing, motivational introduction (forming "artificial" needs and reasons for changes in the behavior of interest initiator manipulative effects).

\section{The skill and proficiency in implementing manipulative action. ${ }^{1}$}

Modern children's manipulation is not new; they concretise portraits manipulators proposed in the last century Shostrom E. ${ }^{9}$ Children's arts and devices have similarities with the manipulation of adolescents ${ }^{10}$ and adults. ${ }^{9}$ This proves that the proven methods in childhood and behavioral strategies are fixed and transferred to the later stages of ontogeny. Understanding the essence of the phenomenon of psychological manipulation in the preschool child, the definition of values education of preschool children it is important to search for the theoretical and methodological foundations of working with manipulative displays of children and adults.

\section{Acknowledgements}

None.

\section{Conflict of interest}

The author declares that there is no conflict of interest. 


\section{References}

1. Kozachek OV. Psychological manipulation of pre-school age children in the family and preschool. Pre-school education in the XXI century: materials Intern. Scientific and practical. Volgograd; 2010:170-173.

2. Dotsenko EL. Psychology manipulation. 2003:53.

3. El'konin DB. Selected psychological works. 1984:560.

4. Slobodchikov VI. Anthropological perspective of national education. Ekaterinburg; 2010:264.

5. Mukhin VS. Psychology: phenomenology development, childhood, adolescence; 1998:456.
6. Smirnova EO. Child psychology. 2003:160.

7. Kulagina IY, Kolyutsky VN. Psychology: The complete life cycle of human development. 2001:464.

8. Ruza AG, Abramova LN. How to deal with complaints of preschool children in kindergarten. Questions of psychology. 1983;4:96-103.

9. Shostrom E. Anti-Carnegie, or man-manipulator. Minsk. 1992:16.

10. Bondarev LV, Kozachek OV. Psychology manipulative communication in adolescence. 2003:138. 